\title{
Potential of Solar-driven CDI Technology for Water Desalination in Egypt
}

\author{
Moustafa El Shafei ${ }^{1}$ and Ashraf Seleym² \\ ${ }^{1}$ Faculty of Engineering, Misr University of Science and Technology, Giza, Egypt \\ ${ }^{2}$ Faculty of Engineering, The British University in Egypt, Tanta, Egypt \\ moustafa.elshafei@must.edu.eg ${ }^{1}$, ashraf.seleym@bue.edu.eg²
}

\begin{abstract}
Freshwater scarcity is one of the most challenging problems facing the world today. Rivers, lakes, and surface ice represent only $1.2 \%$ of the fresh water sources on earth, while ground water represents over $30 \%$ of the potential fresh water. The Egyptian quota from the River Nile is limited to 55 billion $\mathrm{m}^{3} / \mathrm{yr}$, and expected to decrease due to increasing demand of water by other Nile basin countries. According to an Egyptian government report, the total population of Egypt increased from 22 million in 1950 to around 85 million in 2010. This increase in population will continue for decades and it is likely to increase to between $120-150$ million by 2050. Egypt has reached a state where the quantity of water available is imposing limits on its national economic development. As indication of water scarcity, Egypt passed the international threshold value of $1000 \mathrm{~m}^{3} /$ capita/year in the nineties, and it is expected to cross the threshold of absolute water scarcity of $500 \mathrm{~m}^{3} /$ capita/yr by 2025 . Capacitive deionization (CDI) is a relatively new technology that was developed as recently as the late 1960s. In CDI systems, saline water is made to pass between a pair of electrodes connected to a voltage source. Ions are stored inside the pores of electrodes in CDI via the applied electric field strength. CDI is a membrane less technology and the problems of membrane fouling in the Reverse Osmosis technology are not present in CDI. It has the potential to be energy efficient compared with other related techniques and robust technology for water desalination. This paper explores low cost and efficient desalination technologies for brackish water for irrigation and drinking purposes using the abundant solar energy in Egypt.
\end{abstract}

Keywords - solar photovoltaic; capacitive deionization; water desalination.

\section{INTRODUCTION}

Around $75 \%$ of the Earth's surface is covered by water, out of which $97.5 \%$ (for sake of consistency) is in the form of oceans. The remaining percentage is attributed to ice mass, ground water, rivers and lakes [1]. Rivers, lakes, and surface ice represent only $1.2 \%$ of the Fresh water, while ground water represents over $30 \%$ of the potential fresh water. Over 1.5 billion people lack ready access to drinking water and approximately 2.3 billion people suffer from water shortages around the globe [2]. As a result of population growth and the increasing quality of the people lifestyle, it is expected that over two-thirds of the population will be facing fresh water shortage in the near future [3]. Due to the limited Egyptian quota from the River Nile and the continuous increase in population, Egypt has reached a state where the quantity of water available is imposing limits on its national economic development [4].

As such, there is a growing need in Egypt and other MENA countries to explore desalination technologies to meet their growing need for fresh water. Currently, the MENA region accounts for 53.4 of the world production of desalinated water. The World Bank published a study in 2012 [5] that recommended renewable energy desalination as a potential solution to close the water gap in the Middle East and North Africa.

Several water desalination technologies are currently used based on utilization of thermal energy, mechanical energy and electrical energy [6]. The most widely used processes for desalination include membrane separation systems: reverse osmosis (RO) and electro-dialysis (ED); and thermal separations including: multistage flash distillation (MSF), multi-effect distillation (MED) and mechanical vapor compression (MVC). Among these processes, $\mathrm{RO}$ and MSF methods are employed in the bulk of the plants $(90 \%)$ to desalinate seawater worldwide. In $E D$, while being a membrane process, the driving force is a potential applied between two electrodes; the same driving force as the Capacitive Deionization (CDI) process. Among membrane-based plants, $86 \%$ belong to $\mathrm{RO}$ plants while electro-dialysis represents only $14 \%$. 
The CDI [7] has attracted interest in the recent years mostly because of its low energy consumption. The objective of this paper is to explore low cost and efficient desalination technologies for brackish water for irrigation and drinking purposes using the abundant solar energy in Egypt. The development of low cost desalination technology for brackish water would be of great interest not only for Egypt, but for many countries in the Middle East and North Africa as well as many other arid and semi-arid areas in the world.

The rest of this paper is organized as follows: an introduction to the capacitive de-ionization technique is introduced in Section II. Next, in Section III, a CDI model for evaluation of a solar driven CDI cell is proposed. A directly driven $\mathrm{PV} / \mathrm{CDI}$ system is discussed in Section IV.

\section{DESALINATION USING CAPACITIVE DE- IONIZATION}

In CDI systems, saline water is made to pass between a pair of porous electrodes connected to a voltage source. The phenomenon of desalination using CDI is as illustrated in Figure 1. A CDI is a twostep process; the first step is ion adsorption or charging that results in a pure permeate stream where ions are adsorbed in porous charged electrodes. As the voltage is applied to the electrodes, due to the presence of electrostatic field in between the electrodes, there is movement of ions such that the positive ions, or cations, move to the cathode and anions to the anode. Two layers of opposite polarity are formed at the electrode-solution interface, which is referred to as electrical double layer (EDL), and ions are stored in these EDL's. In the next step, voltage is reversed so that the ions get desorbed and flow out of the CDI cell as a brine stream and thus cause regeneration of electrodes. CDI differs from Electrodialysis in the sense that it does not use membranes. The problems of membrane fouling are not present in CDI. It has the potential to be energy efficient, robust technology for water desalination.

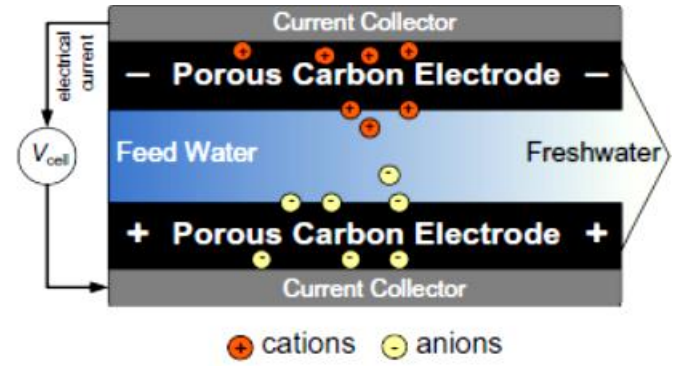

Fig .1. Schematic design of a cell for Capacitive Deionization [7].

The early work in the CDI technology was reported by Farmer et al. in 1995. They showed experimental results of apparatus, which was developed at Lawrence Livermore National Laboratories [8-10], in which they use carbon aerogel as porous electrode material. Since then the process came to be known as Capacitive De-ionization. The recent advances in nanotechnology and carbon nanostructures have recently fueled the interest in Capacitive Deionization process. The basis of the process is a phenomenon called Electrostatic Double Layer (EDL). EDL forms inside the carbon electrodes micropores. The ions are immobilized as they are adsorbed into the electrostatic double layers. These electrical double layers become charged and discharged as the cell voltage is varied and stores and releases the charge. After the micropores get saturated with adsorbed ions, the cell voltage can be reduced to zero or reversed to release the ions from the electrode pores and thus the electrodes are regenerated. A stack of electrode pairs can be used to improve the efficiency of the process. The cell in this case consists of titanium current collector plates, with carbon aerogel or activated carbon glued on both sides by suitable conducting material. The CDI process removes ions from water rather than removing water from the salt and thus requires less energy for desalination. Table I compares the energy required in $\mathrm{kWh} / \mathrm{m}^{3}$ for various desalination technologies. The table clearly shows that CDI has the least energy demand among the existing desalination technologies.

Table 1. ENERGY DEMANDS OF DIFFERENT DESALINATION TECHNOLOGIES [13]

\begin{tabular}{|c|c|}
\hline Desalination method & Energy demand in $\mathbf{~ W h} / \mathbf{m}^{\mathbf{3}}$ \\
\hline MSF & $10-58$ \\
\hline MED & $6-58$ \\
\hline RO & $2-6$ \\
\hline ED & $0.4-8.7$ \\
\hline CDI & $0.1-2.03$ \\
\hline
\end{tabular}


Several authors addressed the comparison between CDI technology and RO desalination technology [7, 13, 15]. A comparison summary is shown in Table II. $\mathrm{RO}$ requires extensive pre-filtering because the membranes are susceptible for fouling, and requires anti-sealant chemical additives. $\mathrm{RO}$ is also very sensitive to disinfectant and cannot tolerate chlorine concentration more than $0.1 \mathrm{ppm}$. Membranes require frequent acid cleaning, which causes serious environmental impacts. On the other hand, CDI does not require special filtering, is immune against fouling, and does not require chemical additives. CDI can work efficiently at high environmental temperatures, while $\mathrm{RO}$ efficiency deteriorates rapidly with higher environmental temperature. The CDI process generally has relatively low energy consumption, which ranged from less than $0.6-1.2 \mathrm{kWh} \mathrm{m}^{-3}$ for total dissolved solids (TDS) removal from brackish water $[7,15]$. The CDI process has about three times lower production cost as compared with a lowpressure RO desalination facility [15]. The initial investment of $\mathrm{CDI}$ is comparable with $\mathrm{RO}$ for the same capacity. However, the operational cost and maintenance cost of CDI is much lower than RO due to the frequent replacement of the RO membranes and maintenance cost of the high pressure pumps. $C D I$ is also space efficient. For example, a CDI unit for brackish water from Voltea [16] produces about $168 \mathrm{~m} 3 /$ day, while its size is $1.1 \times 1.5 \times 2.4=3.96 \mathrm{~m}^{3}$. The specific production capacity per $\mathrm{m} 3$ of space is about $42.2 \mathrm{~m} 3 /$ day. On the other hand, a commercial $\mathrm{RO}$ for brackish water [17] produces $758 \mathrm{~m} 3 /$ day, and has a size of about $33 \mathrm{~m} 3$. The specific production capacity is about $23 \mathrm{~m}^{3} /$ day. This shows clearly that $\mathrm{CDI}$ is space efficient. In the commercial scale, RO systems usually require pre-treatment of inlet water by additive chemicals to reduce the deteriorating effect of fouling on the membranes, which raises health and environmental concerns. On the other hand, $C D I$ is a green technology with minimal impact on the environment.
Table 2. DETAILED COMPARISON BETWEEN CDI AND RO TECHNOLOGIES [14]

\begin{tabular}{|c|c|c|}
\hline Desalination Technology & CDI & RO \\
\hline Pre treatment & Low & High \\
\hline High temp system $^{*}$ & Yes & No \\
\hline Scaling and fouling & Low & High \\
\hline Dynamic TDS adjustment & Yes & No \\
\hline Problematic ions in feed & No & Yes \\
\hline Chlorine tolerance & Yes & No \\
\hline Chemicals & No** & Yes \\
\hline Consumables & Low & High \\
\hline Maintenance & Low & High \\
\hline Energy use & Low & High \\
\hline Operational pressure & Low & High \\
\hline Water recovery & $75-90 \%$ & $20-75 \%$ \\
\hline Operation costs & $\$$ & $\$ \$ \$$ \\
\hline Price & $\$ \$$ & $\$ \$$ \\
\hline
\end{tabular}

* Above $45^{\circ} \mathrm{C} / 110^{\circ} \mathrm{F}$.

${ }^{* *}$ Acid injection may be required in some applications

\section{MODELLING OF CAPACITIVE DE- IONIZATION CELL}

A schematic of a CDI cell as shown in Figure 2. A $\mathrm{CDI}$ cell is basically a conduit of rectangular cross section of width $W_{e}$, length $L_{e}$ and height de. CDI cell consists of electrodes (activated carbon) of thickness $\mathrm{d}_{\mathrm{c}}$, and each electrode of a CDI cell is attached to a current collector. The activated carbon electrode layer is merged and fully in contact with the salty water. The top current collector is connected to a dc voltage signal of $+\mathrm{u}_{1}$ and bottom current collector to a $\mathrm{dc}$ voltage signal of $-\mathrm{u}_{1}$ during purification that causes the anions to move towards anode and cations to move towards cathode. During regeneration, the CDI cell is powered off with zero voltage or a voltage of opposite polarity is applied to the current collectors. The purification and the regeneration steps complete the CDI cycle. The water flows at a flow rate of $q_{\text {in }}$ to the $\mathrm{CDI}$ cell and the flow rate at the exit qo can be controlled using a valve. 


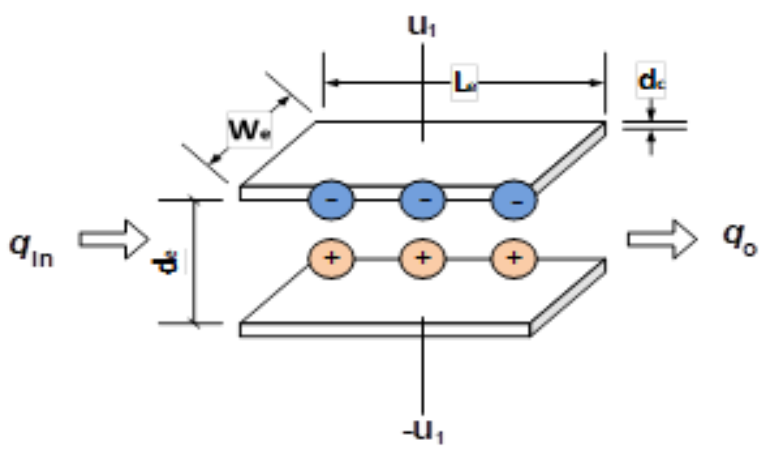

Fig .2. CDI cell operation during purification - anions gets adsorbed on the anode and cations to the cathode.

An electric circuit model of a CDI cell with two electrodes is sh॰own in Figure 3.

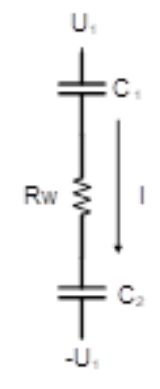

(a)

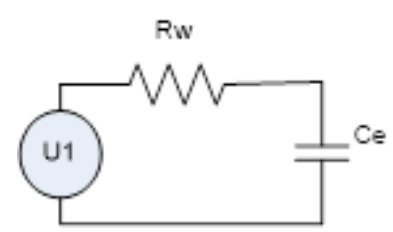

(b)
Fig .3. (a) Electric Circuit model of a CDI, (b) Equivalent electric circuit of a CDI cell.

The top activated carbon electrode capacitance is represented by capacitor $C_{1}$ and bottom electrode capacity is represented by capacitor $\mathrm{C}_{2}$, which is negatively charged. The capacitance associated with both electrodes is equal to maintain charge balance in solution i.e. $C_{1}=C_{2}$. $R_{w}$ is the electrical resistance of the water between the two opposite electrodes and $i$ is the current flowing in the CDI cell through $R_{w}$ resistance. The resistance of water is given by the formula.

$$
R_{w}=\frac{\rho_{e} d_{e}}{A_{c}}
$$

where $A_{c}$ is the physical area of the activated carbon in $\mathrm{m}^{2}, \mathrm{de}_{\mathrm{e}}$ is the distance between the activated carbon electrodes, and $\rho_{e}$ is the resistivity of the water.

The resistivity of water depends on temperature and concentration, and for saline water is given approximately by [11]

$$
\rho_{e} \cong \frac{5}{x\left(1+\alpha_{T}(T-25)\right)}
$$

where $x$ is the concentration of salt in $\mathrm{kg} / \mathrm{m}^{3}$ (or grams $/$ l) and $\alpha_{T}=0.022 /{ }^{\circ} \mathrm{C}$

Let $A_{c}=L_{e} W_{e}$ be the physical Area of the capacitor. The effective area of the capacitance associated with each electrode is given by

$A_{e}=\left(A_{c} d_{c} \rho_{a c}\right) S_{a c}$

where $S_{\mathrm{ac}}$ is the specific surface area of the activated carbon, which is typically around $800-2500 \mathrm{~m}^{2} / \mathrm{gram}$, and $\rho_{c}$ is the density of activated carbon.

The effective capacitance associated with each electrode is given by

$C_{e}=\frac{A_{e} \varepsilon_{0} \varepsilon_{r}}{t_{c s}}$

where $t_{c s}$ is the thickness of the double layer which is of the order of nanometers. The electrical double layer thickness is often approximated as Debye length using Gouy Chapman model [12]. Debye length is given by $\lambda_{D}$ as

$$
\lambda_{D}=\sqrt{\frac{\varepsilon_{r} \varepsilon_{0} R T}{2 F^{2} x}}
$$

Where $\varepsilon_{0}$ is the permittivity of free space, $\varepsilon_{r}$ the relative permittivity of water (78), $R$ is the universal gas constant $\left(8.3144621 \mathrm{~J} \mathrm{~K}^{-1}\right.$ moles $\left.^{-1}\right), F$ is the Faradays constant (96500 coulombs), $x$ is the concentration of salt in bulk solution (macropores), and $T$ is the temperature in Kelvin (297.15 K).

As such during charging and discharging, the CDI cell can be modelled as a super capacitor in a simple RC circuit as shown in Figure 3(b). From the symmetry of the circuit, the equivalent capacitor is basically $\mathrm{C}_{e}=$ $C_{1}=C_{2}$, while the applied voltage is $U_{1}$. The applied voltage is limited to a maximum of 1.5 volts to avoid electrolysis of water into hydrogen and oxygen.

\section{PV DRIVEN CDI CELL}

The researchers will consider here a small CDI system directly driven by a typical low cost PV panel, as in Figure 4. The operation of the system consists of five steps as shown in Table III. At the start of the 
day, Valve $\mathrm{v} 1$ is turned on to allow the raw brackish water to fill the cell, while Valves v2 and v3 are off. When the cell becomes full, Valve $v 1$ is turned off and the excitation voltages E1 and E2 are turned on taking the required power from the PV cells through appropriate electronics. At the sun set, Valve v2 is turned on, and the fresh water is taken from the cell to a fresh water tank. After draining the fresh water, Valve v2 is turned off, and the excitation voltage is connected to zero voltage, while Valve v1 is turned on until the cell is full again. The captured ions now return to the water to form high concentration brine. After sufficient time to ensure all the captured ions have left the activated carbon, the highly salty water is drained through Valve v3. The cycle is then repeated next day.

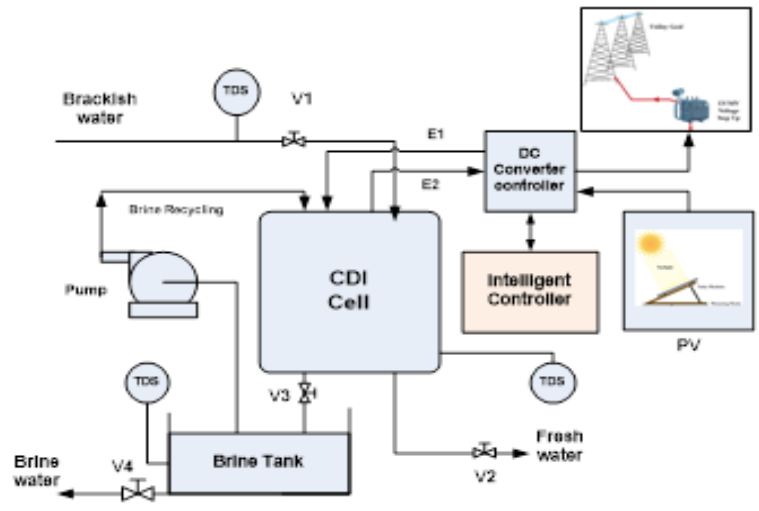

Fig .4. Block diagram of a directly driven CDI by PV solar panels.

In the above steps, the water recovery ratio is basically $50 \%$. In many situations, the brackish water could be brought from deep wells at high cost. As such, higher recovery ratio is desired. Water recovery ratio can be improved by recycling the brine during the regeneration stage. For example, if the brine is recycled three times, the water recovery ratio would be $75 \%$.

The following analysis is based on a small unit driven by a single commercial PV panel. The most common PV panels are approximately $(1 \mathrm{~m} \times 1.5 \mathrm{~m})$ with about $16 \%$ efficiency, producing about 240 Watts at 1000 watts $/ \mathrm{m}^{2}$ solar insolation. With typical solar radiation in Egypt of $5 \mathrm{kWh} /$ day per $\mathrm{m}^{2}$, the expected daily energy from this panel is ES = (1) (1.5) (5.0) (0.16) = $1.2 \mathrm{kWh} /$ day.
Table 3. OPERATION STEPS OF SYSTEM

\begin{tabular}{|c|c|c|c|c|c|}
\hline Step & V1 & V2 & V3 & E1 & E2 \\
\hline 1 & On & off & off & 0 & 0 \\
\hline 2 & Off & off & off & $+\mathrm{U} 1$ & $-\mathrm{U} 1$ \\
\hline 3 & Off & on & off & $+\mathrm{U} 1$ & $-\mathrm{U} 1$ \\
\hline 4 & On & off & off & 0 & 0 \\
\hline 5 & Off & off & on & 0 & 0 \\
\hline
\end{tabular}

The researchers assume that about $30 \%$ losses will occur due to wire and water resistive losses, as such the net energy stored in the capacitance $E_{\text {sn }}=0.84$ $\mathrm{kWh}$. The energy stored in the capacitance is given as

$$
E_{S}=\frac{1}{2} C_{e} U_{1}^{2}
$$

Since the maximum voltage is limited to $\mathrm{V}_{\max }=1.5$ Volts, the required capacitance to store the available solar energy is given by

$C_{e}=\frac{2 E_{S}}{V_{\max }^{2}}=\frac{2(0.84)(3600000)}{(1.5)^{2}}=2,688,000$ Farad

The captured charge, $Q$, by the capacitor

$Q=C_{e} V=4032000 \quad$ Coulombs

They further assume that the cell is used to produce fresh water (permeate) for drinking purpose with total dissolved solids (TDS) of $X_{p}=350$ ppm from brackish water with TDS of $X_{f}=4000$ ppm.

The amount of salt (in $\mathrm{kg}$ ) to be removed is given by

$$
M_{s}=V_{p}\left(X_{f}-X_{p}\right)
$$

where $V_{p}$ is the volume of fresh water (permeate).

The mass of the removed salt is related to the ionic charge in the CDI capacitance by the relation.

$Q=\frac{M_{s}}{M_{W s}} F$

where $F$ is Faraday constant and $M_{W s}$ is the molecular mass of salt. Assume for simplicity the salt is $\mathrm{NaCl}$, with $\mathrm{MWs}=58.44 \mathrm{grm} /$ mole.

Combining equations (3.7), (3.8), and (3.9), it becomes clear that the produced volume $\left(V_{p}\right)$ of fresh water per day can be calculated as 
$V_{p}=\left(\frac{Q}{F}\right)\left(\frac{M_{W s}}{X_{f}-X_{p}}\right)$

Then, the volume of fresh water $V_{p}=699.1$ Liters/day.

In the next analysis, the researchers calculate the physical size of the matching CDI cell. Assume activated carbon with specific area of $S_{\mathrm{ac}}=1500$ $\mathrm{m}^{2} / \mathrm{grm}$, and density of $0.4 \mathrm{grm} / \mathrm{cm}^{3}$ is used in the CDI cells as an electrode layer of thickness $t_{\mathrm{ac}}=2 \mathrm{~mm}$.

From (3.3) and (3.4), the physical area of the capacitor is given by

$$
A_{c}=\frac{1}{d_{c} \rho_{a c} S_{a c}} \frac{C_{e} t_{c s}}{\varepsilon_{0} \varepsilon_{r}}
$$

Then the mass of the activated carbon is given by

$$
M_{A C}=A_{c} d_{c} \rho_{a c}
$$

Using the value of $C_{e}$ in (3.7), the required physical area $A_{c}$ came to about $101 \mathrm{~m}^{2}$, and mass of activated carbon came to about $80 \mathrm{Kg}$ for the entire unit. The design of the cell suggested an array of $50(1 \mathrm{~m} \times 2 \mathrm{~m})$

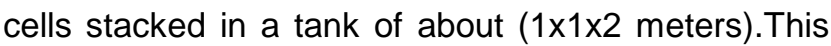
modular system can be repeated to meet the required fresh water production rate.

The efficiency of the system can be improved by reducing the electric losses in the wires and water. The resistance of water can be reduced by having tighter spacing between anodes and cathodes. The wire losses can be reduced by using thick conducting buses. The majority of the stored energy in capacitors can also be recovered during the regeneration cycle by discharging the capacitors using appropriate electronic DC/DC converter which feeds batteries, another secondary CDI stage, or, in large scale projects, return the energy to the power grid.

\section{CONCLUSION}

A directly driven solar powered CDI system was studied. It is shown that a PV module of 240 watts can produce about 700 Litres of drinkable fresh water per day. The adsorption stage is performed during the day time, while the regeneration stage is performed at night. The CDI cell is designed to match the PV and to synchronize its operation with solar power. Several improvements can be introduced to reduce the electric resistive losses and to recover the capacitor energy during the regeneration cycle. The system module can be used for small communities and resorts.

This model can serve as a benchmark to study the performance of CDI system under different configurations, different operating conditions, understanding the effect of different parameters on system performance and also optimization of the system parameters to achieve maximum efficiency.

\section{REFERENCES}

[1] P. Gleick. Water in Crisis: A Guide to the World's Fresh Water Resources. New York: Oxford University Press, 1993.

[2] "Water Crisis | Water Ambassadors Canada." [Online], Available: http://www.waterambassadorscanada.org/watercri sis.html.[ Aug 15, 2017].

[3] U. Water. The United Nations World Water Development Report 3-Water in a Changing World. 2009.

[4] "Water scarcity in Egypt." Ministry of Water Resources and Irrigation, Egypt, February 2014. [Online], Available:

http://www.mfa.gov.eg/SiteCollectionDocuments/ Egypt\%20Water\%20Resources\%20Paper_2014. pdf. [Aug 15, 2017].

[5] World Bank. Renewable Energy Desalination: An Emerging Solution to Close the Middle East and North Africa's Water Gap. MENA development report, World Bank, 2012.

[6] A. Cipollina, M. Giorgio and L.Rizzuti, eds. Seawater Desalination: Conventional and Renewable Energy Processes. Place of publication: Springer Science \& Business Media, 2009.

[7] S. Porada, R. Zhao, A. van der Wal, V. Presser and P. M. Biesheuvel. "Review on the science and technology of water desalination by capacitive deionization." Progress in Materials Science, vol. 58, no. 8, pp. 1388-1442, Oct. 2013.

[8] J. Farmer, D. Fix and G. Mack. "Capacitive deionization of $\mathrm{NaCl}$ and $\mathrm{NaNO} 3$ solutions with carbon aerogel electrodes." Journal of the 
Electrochemical Society, vol. 143, no. 1, p. 159, Jan. 1996.

[9] J. C. Farmer, D.V. Fix, G.V. Mack, R.W. Pekala and J.F. Poco. "Capacitive deionization of $\mathrm{NH} 4 \mathrm{ClO} 4$ solutions with carbon aerogel electrodes." Journal of Applied Electrochemistry, vol. 26, no. 10, pp. 1007-1018, 1996.

[10] J. Farmer. "Method and apparatus for capacitive deionization, electrochemical purification, and regeneration of electrodes." US Patent 5,425,858, 1995.

[11]M. Hayashi. "Temperature-electrical conductivity relation of water for environmental monitoring and geophysical data inversion." Environmental Monitoring and Assessment, vol. 96, no. 1-3, pp. 119-128, Aug. 2004.

[12] O. Stern. "Zur theorie der elektrolytischen doppelschicht." Zeitschrift für Elektrochemie und angewandte physikalische Chemie, vol. 30(2122), pp. 508-516., 1924.

[13] F.A. AlMarzooqi, A. A. Al Ghaferi, I. Saadat and N. Hilal. "Application of capacitive deionisation in water desalination: A review." Desalination, vol. 342, pp. 3-15, Jun. 2014.
[14] Voltea B.V. “Voltea's Technical Bulletin: Technology comparison" [Online], Available: http://voltea.com/wpcontent/uploads/2016/03/402D002_Rev01_TechBulletin_Technology-Comparison-1.pdf. [Äug 15, 2017].

[15]T.J. Welgemoed and C.F. Schutte. "Capacitive deionization technology: An alternative desalination solution." Desalination, vol. 183, Issues 1-3, pp. 327-340, Nov. 2005.

[16] Voltea, Technical specifications of the CDI Industrial Series - IS2 to IS48 Systems. [Online]. Available; http://voltea.com/wpcontent/uploads/2016/03/402D026EN_Rev06-ISTechnical-Specifications.pdf. [Aug 15, 2017]

[17] Pure Aqua, Inc., Industrial Brackish RO Systems. [Online]. Available: https://www.pureaqua.com/industrial-brackishwater-reverse-osmosis-bwro-systems/ [Aug 15, 2017]. 